\title{
The impact of online learning on the education system in the context of the spread of coronavirus infection
}

\author{
Olga Astafeva ${ }^{1, *}$, Evgeny Astafiev ${ }^{2}$, and Inna Osipova ${ }^{1}$ \\ ${ }^{1}$ Financial University under the Government of the Russian Federation, Leningradskiy prospect, 49, \\ 125993, Moscow, Russia \\ ${ }^{2}$ Ufa State Petroleum Technological University, St. Kosmonavtov 1, 450062 Ufa, Russia
}

\begin{abstract}
The globalization of the economy and the development of international cooperation, which have been a key priority for many countries over the past few decades, have shown negative consequences for the whole world when an epidemiological threat arises. The transition to online learning has become virtually the only practical response of the education system to the emerging challenge. As part of the preparation of the scientific work, a sociological survey was conducted among students of economic directions about their attitude to online learning during the pandemic. The survey showed that students are generally satisfied with the organization of training in the online learning format and rather highly assess the readiness of the university and teachers to quickly switch to online learning format. The article highlights the main directions of development of the education system, due to the inevitability of the development of online learning and distance education.
\end{abstract}

\section{Introduction}

In modern conditions, one of the key tasks facing the country's leadership and relevant ministries is to ensure equal access of citizens to education. The current epidemiological situation in different countries contributes to the emergence of a risk to the health of people with a large concentration of them in case of non-compliance with sanitary measures. Teaching students and schoolchildren involves their active interaction and communication with teachers and tutors in small rooms, which is associated with the risk of spreading infection within the group, class, cohort, batch. In this regard, online learning is a forced measure to counter the spread of infection among students, taken by the leaders of educational organizations. Thus, the epidemiological situation in the world has actualized the importance of using modern technical means in teaching and has greatly accelerated the processes of digitalization of certain sectors of the economy.

According to the data provided by the University of Phoenix (USA), during the period of being in quarantine, many people changed their attitude towards their current work, and 51\% of the surveyed respondents answered that they will look for remote work in the future.

\footnotetext{
*Corresponding author: astafeva86@mail.ru
} 
According to a survey by Colliers International, $75 \%$ of Russians surveyed would like to work from home at least one day a week [2]. In a short period of time, many categories of citizens had to master a new format of remote work for them. Teachers from educational organizations are no exception.

Quite rightly many experts suggest that distance learning and online learning should be separated. Online training is based on the use of modern information and communication technologies and is carried out online strictly according to a set schedule. Online training allowed universities to continue working in the face of the pandemic and successfully complete the academic year 2019-2020. Distance education in itself is not a novelty for universities and is actively developing especially in recent decades in the light of the formation of the information society. The term distant education was originally introduced in the University of Wisconsin's correspondence course catalog in 1892. The French National Center for Distance Education (CNED) was founded in 1939 [1]. By the end of the century, the number of distance education institutions of various types and levels exceeded 1,100 [7].

There are two key models for the implementation of distance education: specialized educational organizations using distance learning (single mode model), and educational organizations in which distance education is only part of the overall activity (dual mode model). At the same time, the dual model of implementation of distance education has been dominant in recent years. However, for educational organizations, the use of distance education was the only form of education that made it possible to respond to an unexpected challenge for all participants in the education system.

It should be noted that distance education is becoming more and more popular every year, also due to the growing need of working people for retraining, since with the advent of new professions, it is necessary to develop new competencies so as not to be fired $[4,9]$. Thus, distance education is a convenient way to provide educational services without interrupting the main activity for a large group of people. Companies such as General Motors, Ford, WalMart, Federal Express are actively raising the skills of employees through private corporate educational networks.

Recently, against the background of the general digitalization of society, unprecedented growth rates of educational technologies have been observed [5, 8]. Every year there is a technical re-equipment of the higher education system, which educational organizations spend large sums of money on.

\section{Materials and Methods}

Classic traditional universities, which have resisted new changes in the education system for quite a long time, have actively participated in the transition to distance education in the context of a pandemic and did not stop their activities, having successfully completed the 2019-2020 academic year. According to P. Murphy and M. Nixon, the reasons why many universities in recent decades have resisted the new form of education are related more to philosophical, political and power problems than to technical and financial difficulties [6]. Technical difficulties, the high cost of development and implementation of projects, their high riskiness, etc., were often cited as formal reasons for resistance to the development of distance education. However, these objections are based on resistance to radical changes in the education system associated with the development of distance learning. The resistance of the academic community and society as a whole to distance education is explained by the fact that it conflicts with the established practice of teaching in universities, which presupposes full-time study in large groups. The evidence that the adopted teaching standards in higher educational institutions surpass the recently introduced methods of distance learning are the results of a study of teachers' attitudes towards distance education, which was carried out by the Ministry of Education and Science of the Russian Federation jointly 
with the Institute for Social Analysis and Forecasting of the Russian Presidential Academy of National Economy and Public Administration, according to which $87.8 \%$ of the surveyed teachers believe that classes in their courses are best conducted in the full-time format [3].

As part of the preparation of this scientific article, a sociological survey was conducted among students of the Financial University under the Government of the Russian Federation about their attitude to online learning in the context of a sharp change in the form of education and organization of personal life in the conditions of coronavirus infection. Students of different courses of study at the Financial University took part in the survey.

In general, students rated the organization of training in the online learning rather highly, $61 \%$ of the surveyed students gave grades 4 and 5 on a five-point marking scale, and $67 \%$ of the respondents gave grades 4 and 5 according to the degree of readiness of the university and teachers to quickly switch to the online learning. Among the survey participants, $40.3 \%$ answered that it was convenient for them and they even liked the new format of education, about $30 \%$ indicated that it was convenient to study, but encountered minor difficulties. Among the problems that students had to face, most often were indicated (more than $40 \%$ of respondents):

- some get distracted and do not catch the material when watching lectures;

- there is no working atmosphere at home;

- it is inconvenient to use an online board for solving problems and illustrating graphs;

- a large amount of assigned materials.

Among the advantages of online learning, most students indicated:

- flexibility of the educational process $(61.3 \%)$;

- the ability to combine work with study $(50 \%)$.

$15.3 \%$ of the respondents did not see any advantages in the new form of education.

Most of the surveyed students (61.3\%) felt an increase in the study load when switching to the distance form.

MS Teams was recognized as the most convenient and effective learning service, noted by more than $80 \%$ of surveyed students.

Half of the respondents (50\%) indicated that it is advisable to conduct lectures in an online format. At the same time, the majority of students (62.1\%) would like distance technologies to be used for educational purposes in the future.

Thus, based on the opinion of the majority of students, we can conclude that online learning was quite effective in the current situation of the forced transition to a remote form of work and study in the context of the spread of coronavirus infection.

\section{Results and Discussion}

\section{Novelty in the learning paradigm}

It is obvious that in the light of the ongoing pandemic, changes in the education system, including the introduction of new methods and technologies, and the further active development of distance learning are inevitable, which requires a rethinking of the existing teaching paradigm and identification of key trends in the development of the education system in the current conditions.

- It is important to form an understanding among the main participants in the educational process that distance education and online learning are not a part of the system of additional education, but an important component of the entire educational process of the university. Distance education has historically been considered in the structure of additional education and is presented within the framework of existing organizations as institutes for continuing education (ICE) or centers for professional advancement (CPA), engaged in the 
implementation of additional education programs using distance technologies. With the change in the role of online learning in the general educational process, the structure and form of management of new technologies must change. Therefore, in universities that use distance education and online learning, it is important to ensure the unity of the work of the departments involved in the design, implementation, control, improvement of training courses and programs and the provision of technical means to the main participants in the educational process. Thus, it is necessary to change not the fundamental pedagogical and andragogical foundations of education, but the methods and forms of ensuring and managing the educational process.

- The use of distance education and online learning presupposes a change in the productivity of education through a shift in responsibility towards the student, which is inevitably associated with the transition in the minds of students from the behavior of "consumption" of education to the behavior of "creation". An increase in the productivity of education can be ensured provided that the student begins to feel greater responsibility for his own learning and is ready for conscious independent work in the learning process.

- Distance education and online learning is inevitably associated with a change in the role and behavior of teachers, who should to a greater extent act as mediators, coordinators of study groups and mentors of students, rather than lecturers and seminarians, that is, the role of a teacher-reproducer is becoming a thing of the past [10]. At the same time, training programs should be more focused on professional training and focused on the formation of professional rather than general competencies due to the limitations of the format of interaction "teacher - student".

\section{Conclusions}

The transition to online learning in the spring of 2020 has become a real test for the entire education system. In a short time, teachers had to adapt to the new working conditions using technical means not within the walls of the university, but remotely from home, which disrupted their usual lifestyle and routine and led to stress. For students, the difficulties of learning in a distance format were to a greater extent associated not with technical problems, but with the lack of the possibility of interpersonal communication with teachers and classmates and the lack of a working atmosphere at their location. This form of training, due to its flexibility, makes it possible to successfully combine work and study at a university, which was an undoubted advantage for working students, especially senior students.

The processes taking place in the framework of the development and active use of distance education require deep scientific understanding and the creation of a methodological base in the field of didactics and pedagogy for teaching a new generation of students. At the same time, the transformations affect not only the field of pedagogy, since the changes are not limited to educational processes alone but extend to the organization of the entire system of human knowledge and forms of human capital management.

\section{References}

1. L. Zeniuk, X International scientific and methodological conference New educational technologies at a university (2013), https://elar.urfu.ru/

2. R. Tyshkovsky, Distant work for the top managers: what opportunities did the pandemic open to Russian managers, https://hbr-russia.ru/

3. Teachers expressed their opinion about the forced transition of the educational process from offline to online, https://minobrnauki.gov.ru/ 
4. O.V. Astafeva, E.P. Pecherskaya, T.M. Tarasova, E.V. Korobejnikova, Lecture Notes in Networks and Systems, 84, 382 (2020)

5. O.V. Astafeva, National Interests: Priorities and Security, 15, 4, 772 (2019)

6. A.P. Zhabin, S.A. Shchennikov, A.G. Abrosimov and others, Strategic educational alliances as a mechanism for transforming an innovative educational environment (2008)

7. S.A. Shchennikov, Open distance education (2002)

8. E.P. Pecherskaya, L.V. Averina, L.G. Karanatova, S.A. Kozhevnikova, The European Proceedings of Social \& Behavioural Sciences EpSBS, 365 (2019)

9. A.Sh. Kamaletdinov, A.A. Ksenofontov, Management sciences in the modern world. Collection of scientific conference reports, 279 (2019)

10. Yu. Fukolova, Harvard Business Review, 96 (2018) 